\title{
The fat taste sensitivity and its role in food intake: a randomized controlled study
}

\author{
E.E. Ozturk-Duran and D. Dikmen \\ Nutrition and Dietetics, Faculty of Health Sciences, Hacettepe University, Ankara, Turkey
}

Changes in lifestyle affect eating behavior such as increasing consumption of ready-to-eat foods which have more fat content ${ }^{(1)}$. After consumption of a high fat diet, the hormonal response that forms satiety signals decrease ${ }^{(2,3)}$ and this causes more fat consumption causing increase in body mass index (BMI) ${ }^{(4)}$. This study was designed to determine the relationship between fat taste sensitivity and food intake.

This double-blind randomized study was carried out on 44 non-smoking healthy male subjects between the ages of 19-54 in Ankara. Taste thresholds were assessed by using 3-Alternate Forced Choice Methodology (3-AFC) for oleic acid. Cut-off point for fat threshold was determined as $3.8 \mathrm{mM}$. Individuals having fat threshold under $3.8 \mathrm{mM}$ were classified as hypersensitive and fat threshold over $3.8 \mathrm{mM}$ were classified as hyposensitive. Participants kept their 5-day food consumption records and then food records analyzed by using the BEBIS programme. The relation between variables were analyzed with using SPSS programme.

The mean fat threshold of the hypersensitive $(52.3 \%)$ and hyposensitive $(47.7 \%)$ individuals were $1.48 \pm 1.45 \mathrm{mM}$ and $7.94 \pm 2.65$ $\mathrm{mM}$, respectively. Hypersensitive individuals' total daily energy intake, the percentage of energy from fat were lower than hyposensitive individuals whereas the percentage rate from protein were higher $(\mathrm{p}<0.05)$. Monounsaturated fatty acid (MUFA) and polyunsaturated fatty acid (PUFA) intake were lower in hypersensitive individuals $(p<0.05)$. The mean BMI of hypersensitive individuals was lower than hypersensitive individuals $(p<0.05)$. There was also a positive weak correlation between fat threshold and total fat intake $(\mathrm{r}=0.325, \mathrm{p}=0.032)$.

\begin{tabular}{|c|c|c|c|c|c|c|c|}
\hline \multirow[b]{2}{*}{ Energy and macronutrients } & \multicolumn{7}{|c|}{ Fat taste sensitivity } \\
\hline & Hypersensitive $(\mathrm{n}=23$ ) & SD & $\begin{array}{l}\text { Hyposensitive } \\
(\mathrm{n}=21)\end{array}$ & SD & $\begin{array}{c}\text { Total } \\
(\mathrm{n}=44)\end{array}$ & $\mathrm{SD}$ & $\mathrm{p}$ \\
\hline Energy(kcal) & 1992.94 & 243.85 & 2188.73 & 322.26 & 2086.39 & 297.51 & $0.027^{*}$ \\
\hline Protein $(\%)$ & 16 & $13-24$ & 15 & $11-19$ & 16.04 & $11.0-24.0$ & $0.035 * *$ \\
\hline Carbohydrate $(\%)$ & 49.0 & 4.95 & 47.14 & 4.33 & 48.11 & 4.71 & $0.195^{*}$ \\
\hline Fat $(\%)$ & 34.34 & 5.79 & 37.66 & 4.89 & 35.93 & 5.57 & $0.047^{*}$ \\
\hline $\operatorname{SFA}(\mathrm{g})$ & 27.74 & 10.88 & 31.60 & 6.47 & 30.10 & 9.06 & $0.292 *$ \\
\hline MUFA (g) & 26.21 & 7.60 & 32.40 & 8.43 & 29.17 & 8.51 & $0.014^{*}$ \\
\hline PUFA (g) & 15.99 & 5.58 & 21.15 & 5.51 & 18.45 & 7.00 & $0.013^{*}$ \\
\hline BMI $\left(\mathrm{kg} / \mathrm{m}^{2}\right)$ & 24.5 & 1.77 & 27.6 & 1.83 & 26.05 & 2.40 & $0.000^{*}$ \\
\hline
\end{tabular}

Distribution of nutrient intake according to fat taste sensitivity of individuals (*Independent-Samples T-Test, ** Mann Whitney U Test)

In conclusion, increased fat threshold could increase energy density of the diet and cause more fat consumption in male. The fat threshold is related with the dietary fat intake. Even though fat is proposed as a unique taste, further studies should be planned on the mechanism and definition of the perception of fat taste.

1. Méjean C, Morzel M, Neyraud E et al. (2015) PLoS One 10, e0137473.

2. Liu D, Archer N, Duesing K et al. (2016) Prog Lipid Res 63, 41-49.

3. Stewart J \& Keast R Int J Obes 36, 834-842.

4. Newman LP, Bolhuis DP, Torres SJ et al. (2016) Obesity 24, 328-334. 